\title{
Ventral lateral geniculate input to the medial pons is necessary for visual eyeblink conditioning in rats
}

\author{
Hunter E. Halverson and John H. Freeman ${ }^{1}$ \\ Department of Psychology, University of lowa, lowa City, lowa 52242, USA
}

\begin{abstract}
The conditioned stimulus (CS) pathway that is necessary for visual delay eyeblink conditioning was investigated in the current study. Rats were initially given eyeblink conditioning with stimulation of the ventral nucleus of the lateral geniculate (LGNv) as the CS followed by conditioning with light and tone CSs in separate training phases. Muscimol was infused into the medial pontine nuclei (MPN) after each training phase to examine conditioned response (CR) retention to each CS. The spread of muscimol infusions targeting the MPN was examined with fluorescent muscimol. Muscimol infusions into the MPN resulted in a severe impairment in retention of CRs with the LGNv stimulation and light CSs. A less severe impairment was observed with the tone CS. The results suggest that CS information from the LGNv and light CSs is relayed to the cerebellum through the MPN. Retrograde tracing with fluoro-gold (FG) showed that the LGNv and nucleus of the optic tract have ipsilateral projections to the MPN. Unilateral inputs to the MPN from the LGNv and nucleus of the optic tract may be part of the visual CS pathway that is necessary for visual eyeblink conditioning.
\end{abstract}

The neural substrates of associative motor learning have been studied extensively using eyeblink conditioning (Christian and Thompson 2003; Thompson 2005). Eyeblink conditioning is typically established by pairing a tone or light conditioned stimulus (CS) with an unconditioned stimulus (US) that elicits the eyeblink reflex. An eyeblink conditioned response (CR) emerges over the course of paired training, and the peak of eyelid closure occurs at the onset time of the US. Results from experiments using temporary lesions of the cerebellar deep nuclei or cerebellar cortex indicate that the anterior interpositus nucleus and cerebellar cortex are necessary for acquisition, expression, and extinction of eyeblink conditioning (Krupa et al. 1993; Hardiman et al. 1996; Krupa and Thompson 1997; Garcia and Mauk 1998; Medina et al. 2001; Bao et al. 2002; Freeman et al. 2005a). Blocking cerebellar output with inactivation of the superior cerebellar peduncle, red nucleus, or brainstem motor nuclei selectively blocks CR expression but not acquisition, providing further evidence that learning occurs in the cerebellum (Chapman et al. 1990; Krupa et al. 1993, 1996; Krupa and Thompson 1995).

Sensory stimuli from every modality are sent to the pontine nuclei (PN), which receive projections from the lower brainstem, thalamus, and cerebral cortex (Glickstein et al. 1980; Brodal 1981; Mihailoff et al. 1989; Schmahmann and Pandya 1989; Wells et al. 1989; Knowlton et al. 1993; Campolattaro et al. 2007). Neurons in the PN project CS information to the cerebellum via mossy fibers in the middle cerebellar peduncle that synapse on granule cells in the cerebellar cortex and on neurons in the interpositus nucleus (Bloedel and Courville 1981; Brodal 1981; Steinmetz and Sengelaub 1992; Mihailoff 1993). Lesions of the middle cerebellar peduncle impair eyeblink conditioning with auditory, somatosensory, and visual CSs (Lewis et al. 1987). Bilateral electrolytic lesions of the dorsolateral and lateral pontine nuclei (LPN) block retention of CRs to an auditory CS but have no effect on lightelicited CRs (Steinmetz et al. 1987). Inactivation of the contralateral LPN blocks CRs to a tone CS but not to lateral reticular nucleus stimulation in rabbits (Bao et al. 2000). Moreover, stimulation of the LPN or middle cerebellar peduncle is a sufficient CS for

\footnotetext{
'Corresponding author.
}

Email john-freeman@uiowa.edu; fax (319) 335-0191.

Article is online at http://www.learnmem.org/cgi/doi/10.1101/lm.1572710. eyeblink conditioning (Steinmetz et al. 1986, 1987; Tracy et al. 1998; Bao et al. 2000; Freeman and Rabinak 2004; Freeman et al. 2005b; Campolattaro and Freeman 2008). The findings from the lesion, inactivation, and stimulation studies provide evidence that the PN is the proximal part of the CS pathway for cerebellar learning. These studies also indicate that the LPN is the primary source of auditory CS input to the cerebellum.

Only a few studies have examined the visual CS pathway necessary for eyeblink conditioning. The dorsal and ventral divisions of the lateral geniculate nucleus of the thalamus (LGNd, LGNv), pretectal nuclei, visual cortex (VCTX), and superior colliculus (SC) comprise a hypothesized parallel visual CS pathway for eyeblink conditioning (Koutalidis et al. 1988). Combined lesions of all of these visual areas completely block acquisition, lesions of two visual areas produce a partial impairment, and lesions in one visual area do not impair CR acquisition (Koutalidis et al. 1988). Stimulation of the VCTX, SC, and LGNv support eyeblink conditioning, and each of these structures has a direct unilateral projection to the PN that could be important for eyeblink conditioning (Halverson et al. 2009). The lesion and stimulation studies provide evidence that structures in the hypothesized visual CS pathway are independently capable of supporting conditioning. An important aspect of the visual CS pathway proposed in the Koutalidis et al. (1988) study is distributed projections of each visual area to different regions of the PN. The important projections were hypothesized to be from the VCTX to the rostral portion of the PN, from both the SC and pretectal nuclei to the dorsolateral PN, and the LGNv projection to the medial pontine nuclei (MPN) (Koutalidis et al. 1988). Lesions of the VCTX were substituted for LGN lesions in the Koutalidis et al. (1988) study due to technical problems with animal survival. The LGNv projection to the MPN was therefore not examined in their combined lesion group. Stimulation of the anterior pretectal nucleus is not a sufficient CS to support eyeblink conditioning (Campolattaro et al. 2007). The direct PN projection from the VCTX is not necessary for CR retention to a light CS, as lesions do not prevent eyeblink conditioning to a light CS in dogs or monkeys (Hilgard and Marquis 1935, 1936). Moreover, lesions of the entire cerebral cortex do not prevent acquisition or retention of delay eyeblink conditioning to a tone or light CS in rabbits (Oakley and Russell 1972, 1977). The LGNv and SC, therefore, are 
A

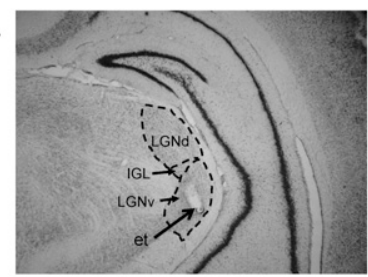

C

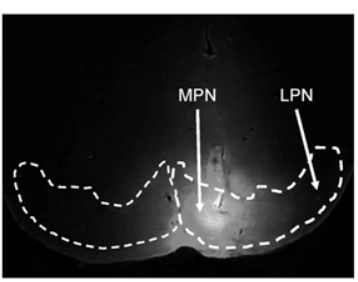

B

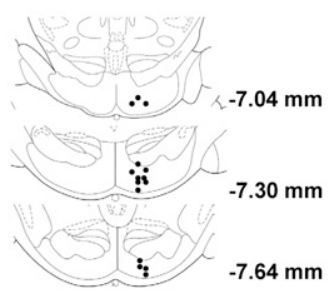

D

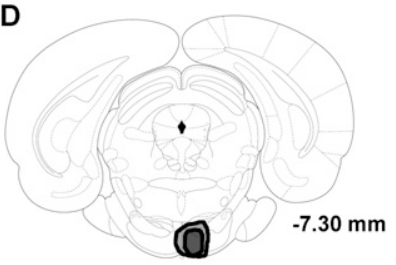

Figure 1. $(A)$ Coronal section of the visual thalamus showing a representative electrode placement in the ventral lateral geniculate (LGNv). (LGNd) Dorsal lateral geniculate; (IGL) intergeniculate leaf; (et) electrode tip. Magnification, $2.5 \times$. (B) Coronal sections of the basilar pontine nuclei with the locations of cannula tips indicated by black dots. (C) Coronal section of the pontine nuclei showing a fluorescent muscimol infusion targeting the medial pontine nuclei (MPN). The cannula tip was in the right MPN. (LPN) Lateral pontine nuclei. Magnification, $4 \times$. (D) Coronal section of the brain showing the largest (light gray) and smallest (dark gray) spread of muscimol.

likely sources of visual input to the PN that is necessary for eyeblink conditioning.

The current experiment investigated whether information from the LGNv and a visual CS (light) share similar inputs into the MPN and whether those inputs are different from an auditory CS. The visual projections to the MPN were also investigated with the retrograde tracer fluoro-gold (FG) to identify structures that may be involved with the relay of CS information during eyeblink conditioning. In the conditioning experiment, rats received three phases of training, with each phase consisting of three acquisition sessions followed by a muscimol infusion into the MPN, and then a saline recovery session. Each rat received unilateral stimulation of the LGNv (contralateral to the trained eye) during phase 1 of training followed by either a tone or light CS in phases 2 and 3 (order of stimulus presentation was counterbalanced). One group received LGNv stimulation in phase 1 followed by a light CS in phase 2 , and a tone CS in phase 3 (SLT). The other group received the tone CS in phase 2, and light CS in phase 3 (STL).

\section{Results}

\section{Cannula and electrode placements}

Stimulation electrode placements in the visual thalamus were verified by examining a series of coronal sections. Electrode placements were in the LGNv $(n=11)$ or the lateral edge of the LGNv $(n=4)$. Figure 1A shows a representative electrode placement in the LGNv.

Cannula placements in the pontine nuclei were verified by examining a series of coronal sections. Placements were in the medial nucleus $(n=8)$, dorsomedial nucleus $(n=5)$, or in the medial ventral nucleus $(n=2)$ (Fig. 1B). No systematic differences were observed in $\mathrm{CR}$ retention to the different stimuli with muscimol infusions through cannula placements in or just outside of the medial pontine nucleus.

\section{Fluorescent muscimol}

The extent of muscimol spread in the MPN was assessed with fluorescent muscimol. The heaviest fluorescent muscimol labeling

was observed in the right medial nucleus. Muscimol also spread to the dorsomedial, reticulotegmental (RtTg), and ventral nuclei and included the medial portion of the left medial nucleus. Figure 1C shows the spread of fluorescent muscimol in the PN from a representative rat. Figure 1D shows the maximum and minimum spread of fluorescent muscimol.

\section{Eyeblink conditioning}

Stimulation of the LGNv as a CS supported rapid CR acquisition during sessions 1-3 in phase 1 (Fig. 2). Substantial transfer was observed during the first session of phases 2 and 3 (sessions 6 and 11) relative to phase 1 . The first session of each training phase was divided into 10-trial blocks to determine whether the transfer between CSs resulted in immediate generalization or rapid acquisition that reflected associative transfer (savings). In phases 2 and 3 , initial responding to the transfer CS (tone or light) was low, but rapid acquisition occurred across blocks (Fig. 3). These findings indicate that immediate generalization was minimal, and performance during the first transfer session in phases 2 and 3 was primarily related to savings. No group differences in CR percentage were observed between the two CS sequences (SLT and STL) for the session or block data. The data were, therefore, pooled for each CS sequence for further analysis.

Analyses were run on the muscimol retention tests to investigate differences in CR retention to $L G N v$ stimulation, light, and tone CSs during MPN inactivation (Fig. 2). A repeatedmeasures ANOVA on the CR percentage data for all trials during the muscimol retention tests, the sessions prior to the muscimol tests, and the sessions after the muscimol tests for each CS (sessions 3-5, 8-10, and 13-15) revealed an interaction of the stimulus and session factors $\left(F_{(4,84)}=37.70, P<0.0001\right)$. Post-hoc tests indicated that rats showed fewer CRs on the LGNv stimulation, light, and tone retention tests than on the last acquisition session and saline recovery sessions for each CS $(P<0.05)$ (Fig. 2$)$. Post-hoc tests also indicated that rats showed fewer CRs during LGNv and light CSs following muscimol infusions relative to the tone CS ( $P<0.05$; Fig. 2), indicating that muscimol infusions into the MPN had a larger effect on light-evoked responses than to tone responses.

\section{Other behavioral effects of muscimol}

All rats given muscimol infusions into the MPN walked slowly counterclockwise in a circle within the home cage and training apparatus. There were no signs of ataxia or abnormal eye movements.

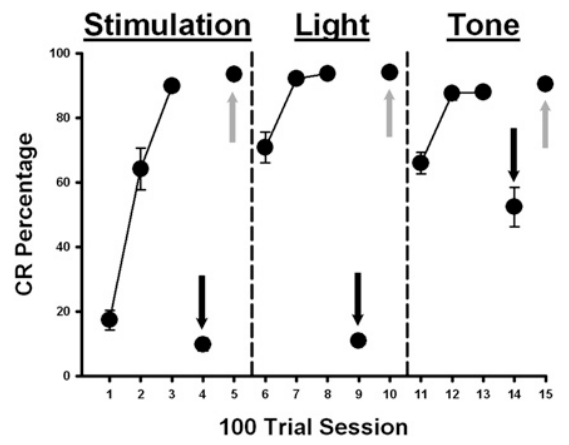

Figure 2. Mean $\pm S E$ conditioned response $(C R)$ percentage for rats given training with a ventral lateral geniculate stimulation (LGNv) CS (sessions 1-5), a light CS (sessions 6-10), and a tone CS (sessions 11-15) in different phases of training. Rats received muscimol infusions into the MPN (black arrows) on sessions 4, 9, and 14. Rats received saline infusions into the MPN (gray arrows) on sessions 5, 10, and 15. Muscimol blocked CRs with both LGNv stimulation (session 4) and light CSs (session 9) and had a partial effect on retention to the tone CS (session 14). 


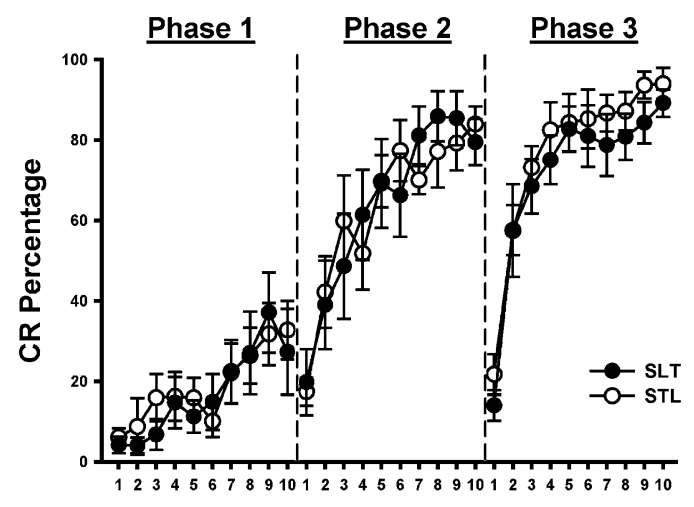

10-Trial Block

Figure 3. Mean $\pm S E$ conditioned response $(C R)$ percentage in blocks of 10 trials during the first session of phase 1 (session 1), phase 2 (session 6 ), and phase 3 (session 11) of training for rats given one of two training sequences: (1) LGNv stimulation $\rightarrow$ light $\rightarrow$ tone (SLT) or (2) LGNv stimulation $\rightarrow$ tone $\rightarrow$ light (STL).

The amplitude and latency of the eyeblink unconditioned response were unaffected by the muscimol infusions.

\section{FG retrograde tracing}

Examination of the FG injection sites in the right PN indicated strong uptake in the MPN. Three of the six injection sites included the medial, ventral, and part of the RtTg PN (Fig. 4B). The extent of these FG injections was similar to the extent of muscimol inactivation in the behavioral experiment (Fig. 1C,D). Two smaller injection sites included only the medial nucleus and medial third of the ventral nucleus (Fig. 4A). The sixth injection site was more dorsal, primarily within the RtTg and dorsomedial pontine nucleus. None of the injections resulted in uptake of FG within the lateral or dorsolateral PN.

Retrogradely labeled neurons were observed ipsilateral to the infusion site, primarily in the LGNv (Fig. 5), anterior pretectal nucleus (APT; Fig. 6), and nucleus of the optic tract (OT) (Fig. 6). Sparse labeling was observed in the deep layers of the superior colliculus, but no labeled neurons were detected in the visual cortex. The smaller injections that were restricted primarily to the medial pontine nucleus and medial third of the ventral nucleus resulted in labeled neurons only within the ipsilateral LGNv. The $\mathrm{RtTg/dorsomedial} \mathrm{PN} \mathrm{injection} \mathrm{yielded} \mathrm{labeled} \mathrm{neurons} \mathrm{in} \mathrm{the}$ ipsilateral LGNv and OT. Retrograde labeling was also observed in the contralateral cerebellar dentate or interpositus nuclei for all injection sites (Fig. 7).

\section{Discussion}

Acquisition of eyeblink conditioning was rapid with LGNv stimulation as the CS in rats. Savings was evident when the rats were switched from LGNv stimulation to a light CS. Retention of eyeblink conditioning with LGNv stimulation, light, or tone CSs was impaired by muscimol inactivation of the MPN contralateral to the conditioned eye. However, inactivation of the MPN produced a much larger impairment of retention with the LGNv stimulation and light CSs relative to the tone CS.

Stimulation of the LGNv contralateral to the conditioned eye was a sufficient CS for eyeblink conditioning in the current study. The LGNv and other visual areas have exclusively ipsilateral projections to the MPN (Figs. 5, 6), and unilateral inactivation of the MPN contralateral to the conditioned eye impaired retention with the LGNv stimulation CS (Fig. 2). These results suggest that the necessary neural circuitry for a visual CS includes unilateral projections to the MPN from visual areas and the MPN projec-

tions to the cerebellum. With a light CS, visual stimulation is conveyed bilaterally to the visual system and then to both MPN. In rats, this bilateral visual input to the MPN, and in turn the cerebellum, results in bilateral conditioning, even with a unilateral US (Campolattaro and Freeman 2009). Thus, the necessary visual CS pathway for eyeblink conditioning is unilateral for each eye, but bilateral CS presentation results in bilateral conditioning.

Substantial savings was observed to both tone and light CSs following conditioning with the LGNv stimulation CS. The observation of rapid transfer from one CS modality to another is not surprising (Kehoe et al. 1984; Schreurs and Kehoe 1987; Kehoe and Napier 1991; Campolattaro and Freeman 2009). However, the finding of equivalent transfer from LGNv stimulation to tone and light CSs was unexpected. A possible explanation for the substantial transfer from LGNv stimulation to the tone CS, despite the partial segregation of CS inputs to the pontine nuclei, is that neurons within the cerebellum are activated by auditory and visual mossy fiber inputs (Tracy et al. 2001). Multimodal neurons in the cerebellum may develop learning-related plasticity to the tone and light CSs rapidly after conditioning with LGNv stimulation and thus support savings in phases 2 and 3.

Inactivation of the MPN produced a more severe retention deficit with visual CSs than the auditory CS in the current study. A previous study showed that muscimol inactivation of the LPN produced a more severe retention deficit with auditory CSs relative to a light CS (Halverson and Freeman 2009). Partial deficits were seen, however, with a visual CS during LPN inactivation and with an auditory CS during MPN inactivation. The findings of these two studies suggest that auditory and visual sensory stimulation is partially segregated within the PN. The partial segregation hypothesis is somewhat inconsistent with the findings of a study that found blockade of retention with an auditory CS and completely unimpaired acquisition with a visual CS following lesions of the LPN in rabbits (Steinmetz et al. 1987). On the other hand, the partial segregation hypothesis is consistent with anatomical studies that show visual projections to both the LPN and MPN (Graybiel 1974; Ribak and Peters 1975; Holstege and Collewijn 1982; Wells et al. 1989; Moore et al. 2000). Localization was limited in the current study due to the spread of muscimol, indicating that additional studies using focal lesions of the MPN and LPN are needed to determine the extent to which sensory inputs are segregated within the PN in rats. Moreover, species differences in sensory input or neuronal organization within the pontine nuclei might account for the differences between the results of this study and the previous studies using rabbits.

Based on the effects of combined lesions of the LGN, pretectal nuclei, superior colliculus, and VCTX on acquisition of eyeblink conditioning, Koutalidis et al. (1988) concluded that the major

A

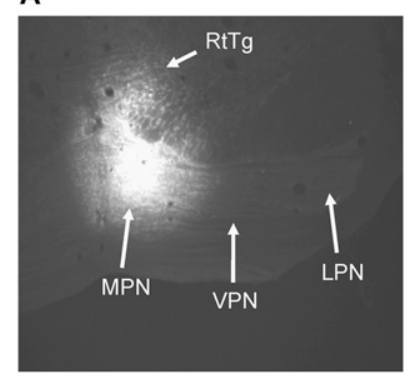

Figure 4. $(A)$ Coronal section of the pontine nuclei showing one of the smaller fluoro-gold infusion sites in the MPN. (B) Coronal section of the pontine nuclei showing one of the larger FG infusions in the MPN. (LPN) Lateral pontine nucleus; (MPN) medial pontine nucleus; (RtTg) reticulotegmental nucleus; (VPN) ventral pontine nucleus. Magnification, $4 \times$. 
A

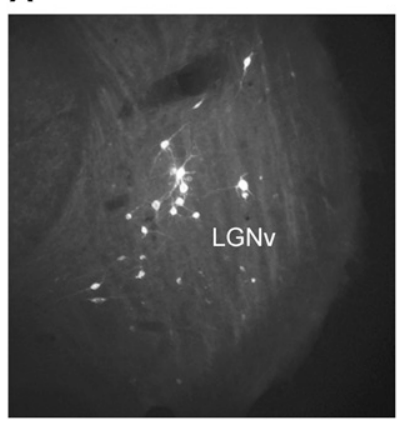

B

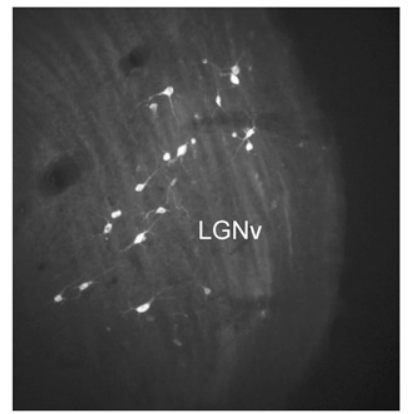

Figure 5. $(A, B)$ Coronal sections of the visual thalamus showing two examples of FG-labeled neurons in the ventral lateral geniculate (LGNv). Magnification, $4 \times$.

visual system projections to the PN constitute a bilateral parallel visual CS pathway. However, results of the current study and previous studies provide evidence that the necessary visual CS pathway for delay eyeblink conditioning may include less of the visual system than proposed by Koutalidis et al. Retention of eyeblink conditioning with either LGNv stimulation or a light as the CS was severely impaired by unilateral inactivation of the MPN. The MPN receives monosynaptic inputs from the ipsilateral LGNv, OT, and anterior pretectal nucleus (Figs. 5, 6). The superior colliculus and visual cortex send large projections primarily to the lateral and dorsolateral pontine nuclei, which were not affected by the muscimol infusions. The anatomical distribution of visual inputs to the pontine nuclei coupled with the deficit in visual conditioning following inactivation of the MPN suggest that the visual CS pathway may include only the LGNv, OT, and pretectal nuclei. Furthermore, stimulation of the anterior pretectal nucleus does not support robust eyeblink conditioning (Campolattaro et al. 2007), suggesting that the LGNv and OT are the necessary visual system components of the visual projections to the MPN. Additional evidence that the VCTX is not an essential component of the visual CS pathway comes from studies showing that lesions of the visual cortex or decortication do not abolish visual delay conditioning (Hilgard and Marquis 1935, 1936; Oakley and Russell 1972 , 1977). In the absence of additional data, our preliminary hypothesis is that the necessary visual CS pathway for delay conditioning in rats includes parallel projections from the LGNv and OT to the MPN (Fig. 8). It is possible that species differences in visual projections to the pontine nuclei account for differences in findings of the Koutalidis et al. (1988) study conducted in rabbits and the results of our studies in rats.

The findings of the current study suggest that visual CS input to the cerebellum is projected through the MPN in rats. Sensory input to the PN is partially segregated, with predominantly visual input to the MPN and predominantly auditory input to the LPN. Our hypothetical model of the visual CS pathway necessary for eyeblink conditioning consists of convergent projections from the LGNv and OT to the MPN contralateral to the conditioned eye (Fig. 8). The initial findings from the current study in rats and the Koutalidis et al. (1988) study in rabbits support this hypothesized model of the visual CS pathway, but additional work is needed to determine which visual inputs to the MPN are necessary for eyeblink conditioning and how neurons in these areas contribute to the relay of CS input to the cerebellum.

\section{Materials and Methods}

\section{Subjects}

The subjects were 21 male Long-Evans rats (250-400 g). The rats were housed in the animal colony in Spence Laboratories of
Psychology at the University of Iowa (Iowa City, IA). All rats were maintained on a 12-h light/dark cycle and given ad libitum access to food and water.

\section{Surgery}

One week before training, rats were removed from their home cages and anesthetized with isoflurane. After the onset of anesthesia, electromyograph (EMG) electrodes (stainless steel) were implanted into the upper left orbicularis oculi muscle. The reference electrode was a silver wire attached to a stainless steel skull screw. The EMG electrode leads terminated in gold pins in a plastic connector. A bipolar stimulating electrode (Plastics One) for delivering the shock US was implanted subdermally, caudal to the left eye. A 23-gauge guide cannula was implanted $2.0 \mathrm{~mm}$ dorsal to the right medial pontine nucleus. A 30-gauge stylet was inserted into the guide cannula and extended $1.0 \mathrm{~mm}$ from the end of the guide. The stereotaxic coordinates taken from bregma for the cannula were $7.4 \mathrm{~mm}$ posterior, $0.6 \mathrm{~mm}$ lateral, and 9.2 $\mathrm{mm}$ ventral to the skull surface for the medial pontine nucleus. A bipolar stimulating electrode was implanted into the right LGNv. The stereotaxic coordinates taken from bregma for the LGNv electrode were $4.5 \mathrm{~mm}$ posterior, $4.2 \mathrm{~mm}$ lateral, and $6.2 \mathrm{~mm}$ ventral to the skull surface. The plastic connector housing the EMG electrode leads, both bipolar stimulating electrodes, the guide cannula, and three skull screws were secured to the skull with Osteobond copolymer bone cement (Zimmer). Animals were maintained on Sulfatrim (Hi-Tech Pharmacal Co.) in water for $4 \mathrm{~d}$ after surgery.

\section{Muscimol infusion procedure}

Before the muscimol infusions, the stylet was removed from the guide cannula and replaced with a 30-gauge infusion cannula that extended $2.0 \mathrm{~mm}$ beyond the guide cannula. The infusion cannula was connected to polyethylene tubing (PE 10; 110-120 cm), which was connected to a $10-\mu \mathrm{L}$ gas-tight syringe (Hamilton). The syringe was placed in an infusion pump (Harvard Apparatus), and $0.2 \mu \mathrm{L}$ of muscimol $(10 \mathrm{mM}, \mathrm{pH} 7.4)$ or saline was infused over $2 \mathrm{~min}$ at a rate of $6 \mu \mathrm{L} / \mathrm{h}$. Fluorescent muscimol $(0.2 \mu \mathrm{L}, 10 \mathrm{mM}$, pH 7.4) was also infused into the MPN 50 min before perfusion. Fluorescent muscimol was visualized using a Nikon Diaphot 300 Microscope. Images were acquired with a computer-assisted CCD camera (QImaging Retiga 2000R) and digital imaging system (Image-Pro Discovery, Media Cybernetics).

\section{Apparatus}

The conditioning apparatus has been described in detail previously (Halverson and Freeman 2006; Campolattaro et al. 2007). Training occurred in conditioning chambers that were within sound-attenuating chambers (BRS/LVE). Electrode leads from the rat's headstage were connected to peripheral equipment by lightweight cables and commutators that allowed the rats to move during conditioning. A desktop computer controlled the delivery of stimuli and the recording of eyelid EMG activity (JSA Designs).

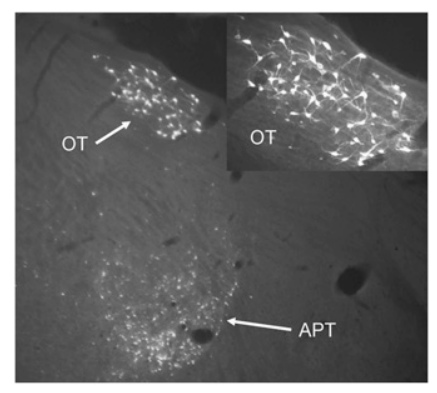

Figure 6. Coronal section showing FG-labeled neurons in the anterior pretectal nucleus (APT) and nucleus of the optic tract (OT). (Inset) Higher magnification shows the OT. Labeling was exclusively ipsilateral to the injection site. Magnification, $4 \times$ and $20 \times$. 


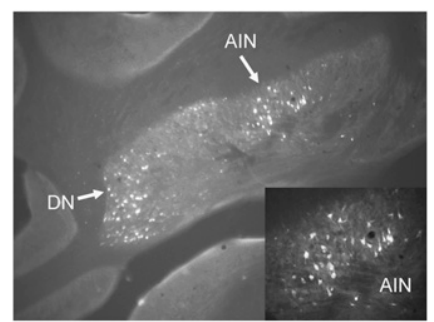

Figure 7. Coronal section of the cerebellum showing FG-labeled neurons in the dentate nucleus (DN) and anterior interpositus nucleus (AIN). Labeling was primarily contralateral to the injection site. Magnification, $4 \times$ and $20 \times$.

\section{Conditioning procedure}

The rats were given $5 \mathrm{~min}$ of adaptation to the chamber before each training session. They were initially given three sessions of paired delay eyeblink conditioning in phase 1 with an LGNv stimulation CS (400-msec train of biphasic pulse [60-100 $\mu \mathrm{A}], 50 \mathrm{~Hz}$ ) and periorbital shock US (25 msec), which was adjusted to two times the threshold for eliciting a discrete eyeblink (2-4 mA). The LGNv stimulation intensity for each rat was set before training by increasing the test current until a behavioral response was observed. The current was then decreased in $5-\mu \mathrm{A}$ increments until there was no observable behavioral response (Campolattaro et al. 2007; Halverson and Freeman 2009). The rats were then given muscimol infusions into the MPN 40 min before a retention test followed by a recovery session with a saline infusion. Rats were then given the same training with tone $(400 \mathrm{msec}, 2.0 \mathrm{kHz}, 85 \mathrm{~dB})$ and light (400 msec, $4 \mathrm{~W}$, white light) CSs in phases 2 and 3 that were counterbalanced between groups (SLT and STL). Each of the daily sessions of delay eyeblink conditioning consisted of 100 trials, with a pseudorandom distribution of intertrial intervals between 18 and $42 \mathrm{sec}$ that averaged 30 sec. Each 400-msec CS coterminated with a 25-msec shock US, yielding an interstimulus interval of $375 \mathrm{msec}$. Daily training sessions, retention tests, and recovery sessions consisted of 10 blocks of nine paired CS-US presentations followed by a CS alone trial. The values relayed to the computer software from an integrator were voltage values of integrated EMG activity. The CR threshold was set to $0.4 \mathrm{~V}$ above the amplified and integrated EMG activity at baseline. The EMG baseline was usually zero, except for a slight DC offset. Integrated EMG responses that exceeded the threshold value during the first $80 \mathrm{msec}$ of the CS period were considered startle responses to the CS; responses that exceed the threshold value during the last $295 \mathrm{msec}$ of the ISI were considered CRs; responses that crossed the threshold after US onset were defined as URs.

\section{Histology}

After training, the rats were euthanized with a lethal injection of sodium pentobarbital $(150 \mathrm{mg} / \mathrm{kg})$ and transcardially perfused with $100 \mathrm{~mL}$ of physiological saline followed by $300 \mathrm{~mL}$ of $10 \%$

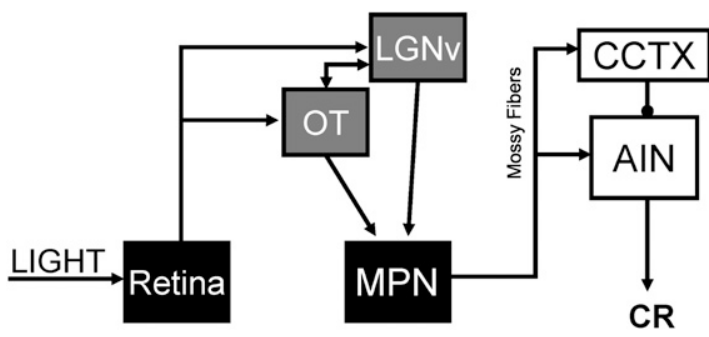

Figure 8. Hypothesized visual CS pathway necessary for delay eyeblink conditioning. Inputs from the retina to the ventral lateral geniculate (LGNv) and nucleus of the optic tract (OT) are relayed to the cerebellar cortex (CCTX) and anterior interpositus nucleus (AIN) via the medial pontine nuclei (MPN). neutral buffered formalin (Surgipath). After perfusion, the brains were postfixed in the same fixative for a minimum of $24 \mathrm{~h}$, cryoprotected in a $30 \%$ sucrose-formalin solution, and subsequently sectioned at $50 \mu \mathrm{m}$ with a sliding microtome. Sections were then stained with thionin. The location of the cannula and electrode placements was then verified using a light microscope (Leica DMLS) and a stereotaxic brain atlas (Paxinos and Watson 1998).

\section{Retrograde labeling with FG}

Rats $(n=6)$ were removed from their home cages and anesthetized with isoflurane. After the onset of anesthesia, a 32-gauge infusion cannula was lowered to the MPN. The stereotaxic coordinates taken from bregma for the cannula were $7.4 \mathrm{~mm}$ posterior, 0.6 $\mathrm{mm}$ lateral, and $10.2 \mathrm{~mm}$ ventral to the skull surface. The infusion cannula was allowed to rest for $5 \mathrm{~min}$ after lowering before initiating the infusion. After $5 \mathrm{~min}, 0.05 \mu \mathrm{L}$ of $4.0 \%$ FG (Fluorochrome, LLC) was infused into the MPN at a rate of $1.0 \mu \mathrm{L} / \mathrm{h}$ over $3 \mathrm{~min}$. The infusion cannula was left in place for $10 \mathrm{~min}$ after the end of the infusion to prevent back flow. The post infusion survival time was $14 \mathrm{~d}$. Rats were then prefused and the brains were sectioned at $50 \mu \mathrm{m}$ with a sliding microtome. Slides were then cleared with xylenes (Fisher Scientific) and coverslipped with DPX (EMS). Labeled neurons were visualized using a Nikon Diaphot 300 Microscope that was equipped with a UV filter. Images were acquired with a computer-assisted CCD camera (QImaging Retiga 2000R) and digital imaging system (Image-Pro Discovery, Media Cybernetics).

\section{Acknowledgment}

This research was supported by National Institute for Mental Health grant MH080005 to J.H.F.

\section{References}

Bao S, Chen L, Thompson RF. 2000. Learning-and cerebellum-dependent neuronal activity in the lateral pontine nucleus. Behav Neurosci 114: 254-261.

Bao S, Chen L, Kim JJ, Thompson RF. 2002. Cerebellar cortical inhibition and classical eyeblink conditioning. Proc Natl Acad Sci 99: 1592-1597.

Bloedel JR, Courville L. 1981. Cerebellar afferent systems. In Handbook of physiology, section I: The nervous system, Vol. II (ed. JM Brookhart et al.), pp. 735-830. Williams and Wilkins, Baltimore, MD.

Brodal A. 1981. Neurological anatomy. Oxford University Press, New York.

Campolattaro MM, Freeman JH. 2008. Eyeblink conditioning in 12-day old rats using pontine stimulation as the conditioned stimulus. Proc Natl Acad Sci 105: 8120-8123.

Campolattaro MM, Freeman JH. 2009. Cerebellar inactivation impairs cross modal savings of eyeblink conditioning. Behav Neurosci 123: 292302.

Campolattaro MM, Halverson HE, Freeman JH. 2007. Medial auditory thalamic stimulation as a conditioned stimulus for eyeblink conditioning in rats. Learn Mem 14: 152-159.

Chapman PF, Steinmetz JE, Sears LL, Thompson RF. 1990. Effects of lidocaine injection in the interpositus nucleus and red nucleus on conditioned behavioral and neural responses. Brain Res 537: 149-156.

Christian KM, Thompson RF. 2003. Neural substrates of eyeblink conditioning: Acquisition and retention. Learn Mem 11: 427-455.

Freeman JH, Rabinak CA. 2004. Eyeblink conditioning in rats using pontine stimulation as a conditioned stimulus. Integr Physiol Behav Sci 39: 180191.

Freeman JH, Halverson HE, Poremba A. 2005a. Differential effects of cerebellar inactivation on eyeblink conditioned excitation and inhibition. J Neurosci 25: 889-895.

Freeman JH, Rabinak CA, Campolattaro MM. 2005b. Pontine stimulation overcomes developmental limitations in the neural mechanisms of eyeblink conditioning. Learn Mem 12: 255-259.

Garcia KS, Mauk MD. 1998. Pharmacological analysis of cerebellar contributions to the timing and expression of conditioned eyelid responses. Neuropharmacology 37: 471-480.

Glickstein M, Cohen JL, Dixon B, Gibson A, Hollins M, Labossiere E, Robinson F. 1980. Corticopontine visual projections in macaque monkeys. J Comp Neurol 190: 209-229.

Graybiel AM. 1974. Visuo-cerebellar and cerebello-visual connections involving the ventral lateral geniculate nucleus. Exp Brain Res 20: 303-306. 
Halverson HE, Freeman JH. 2006. Medial auditory thalamic nuclei are necessary for eyeblink conditioning. Behav Neurosci 120: 880-887.

Halverson HE, Freeman JH. 2009. Medial auditory thalamic input to the lateral pontine nuclei is necessary for auditory eyeblink conditioning. Neurobiol Learn Mem doi: 10.1016/j.nlm.2009.08.008.

Halverson HE, Hubbard EM, Freeman JH. 2009. Stimulation of the lateral geniculate, superior colliculus, or visual cortex is sufficient for eyeblink conditioning in rats. Learn Mem 16: 300-307.

Hardiman MJ, Ramnani N, Yeo CH. 1996. Reversible inactivations of the cerebellum with muscimol prevent the acquisition and extinction of conditioned nictitating membrane responses in the rabbit. Exp Brain Res 110: $235-247$.

Hilgard ER, Marquis DG. 1935. Acquisition, extinction, and retention of conditioned lid responses to light in dogs. J Comp Psychol 19: 2958 .

Hilgard ER, Marquis DG. 1936. Conditioned eyelid responses in monkeys, with a comparison of dog, monkey, and man. Psychol Monogr 47: 186-198.

Holstege G, Collewijn H. 1982. The efferent connections of the nucleus of the optic tract and the superior colliculus in the rabbit. J Comp Neurol 209: 139-175.

Kehoe EJ, Napier RM. 1991. Temporal specificity in cross-modal transfer of the rabbit nictitating membrane response. J Exp Psychol Anim Behav Process 17: 26-35.

Kehoe EJ, Morrow LD, Holt PE. 1984. General transfer across sensory modalities survives reductions in the original conditioned reflex in the rabbit. Anim Learn Behav 12: 129-136.

Knowlton BJ, Thompson JK, Thompson RF. 1993. Projections from the auditory cortex to the pontine nuclei in the rabbit. Behav Brain Res 56: 23-30.

Koutalidis O, Foster A, Weisz D. 1988. Parallel pathways can conduct visual CS information during classical conditioning of the NM response. I Neurosci 8: 417-427.

Krupa DJ, Thompson RF. 1995. Inactivation of the superior cerebellar peduncle blocks expression but not acquisition of the rabbit's classically conditioned eye-blink response. Proc Natl Acad Sci 92: 5097-5101.

Krupa DJ, Thompson RF. 1997. Reversible inactivation of the cerebella interpositus nucleus completely prevents acquisition of the classically conditioned eyeblink response. Learn Mem 3: 545-556.

Krupa DJ, Thompson JK, Thompson RF. 1993. Localization of a memory trace in the mammalian brain. Science 260: 989-991.

Krupa DJ, Weng J, Thompson RF. 1996. Inactivation of brainstem motor nuclei blocks expression but not acquisition of the rabbit's classically conditioned eyeblink response. Behav Neurosci 110: 219-227.

Lewis LJ, Lo Turco JJ, Solomon PR. 1987. Lesions of the middle cerebellar peduncle disrupt acquisition and retention of the rabbit's classically conditioned nictitating membrane response. Behav Neurosci 101: 151157.

Medina JF, Garcia KS, Mauk MD. 2001. A mechanism for savings in the cerebellum. J Neurosci 21: 4081-4089.
Mihailoff GA. 1993. Cerebellar nuclear projections from the basilar pontine nuclei and nucleus reticularis tegmenti pontis as demonstrated with PHA-L tracing in the rat. J Comp Neurol 330: 130-146.

Mihailoff GA, Kosinski RJ, Azizi SA, Border BG. 1989. Survey of noncortical afferent projections to the basilar pontine nuclei: A retrograde tracing study in the rat. J Comp Neurol 282: 617-643.

Moore RY, Weis R, Moga MM. 2000. Efferent projections of the intergeniculate leaflet and the ventral lateral geniculate nucleus in the rat. J Comp Neurol 420: 398-418.

Oakley DA, Russell IS. 1972. Neocortical lesions and Pavlovian conditioning. Physiol Behav 8: 915-926.

Oakley DA, Russell IS. 1977. Subcortical storage of Pavlovian conditioning in the rabbit. Physiol Behav 18: 931-937.

Paxinos G, Watson C. 1998. The rat brain in stereotaxic coordinates. Academic Press, New York.

Ribak CE, Peters A. 1975. An autoradiographic study of the projections from the lateral geniculate body of the rat. Brain Res 92: 341-368.

Schmahmann JD, Pandya DN. 1989. Anatomical investigation of projections to the basis pontis from posterior parietal association cortices in rhesus monkey. J Comp Neurol 289: 53-73.

Schreurs BG, Kehoe EJ. 1987. Cross-modal transfer as a function of initial training level in classical conditioning with the rabbit. Anim Learn Behav 15: $47-54$.

Steinmetz JE, Sengelaub DR. 1992. Possible conditioned stimulus pathway for classical eyelid conditioning in rabbits. I. Anatomical evidence for direct projections from the pontine nuclei to the cerebellar interpositus nucleus. Behav Neural Biol 57: 103-115.

Steinmetz JE, Rosen DJ, Chapman PF, Lavond DG, Thompson RF. 1986. Classical conditioning of the rabbit eyelid response with a mossy-fiber stimulation CS: I. Pontine nuclei and middle cerebellar peduncle stimulation. Behav Neurosci 100: 878-887.

Steinmetz JE, Logan CG, Rosen DJ, Thompson JK, Lavond DG, Thompson RF. 1987. Initial localization of the acoustic conditioned stimulus projection system to the cerebellum essential for classical eyelid conditioning. Proc Natl Acad Sci 84: 3531-3535.

Thompson RF. 2005. In search of memory traces. Annu Rev Psychol 56: 1-23.

Tracy JA, Thompson JK, Krupa DJ, Thompson RF. 1998. Evidence of plasticity in the pontocerebellar conditioned stimulus pathway during classical conditioning of the eyeblink response in the rabbit. Behav Neurosci 112: 267-285.

Tracy JA, Britton GB, Steinmetz JE. 2001. Comparison of single unit responses to tone, light, and compound conditioned stimuli during rabbit classical eyeblink conditioning. Neurobiol Learn Mem 76: 253-267.

Wells GR, Hardiman MJ, Yeo CH. 1989. Visual projections to the pontine nuclei in the rabbit: Orthograde and retrograde tracing studies with WGA-HRP. J Comp Neurol 279: 629-652.

Received July 31, 2009; accepted in revised form November 6, 2009. 


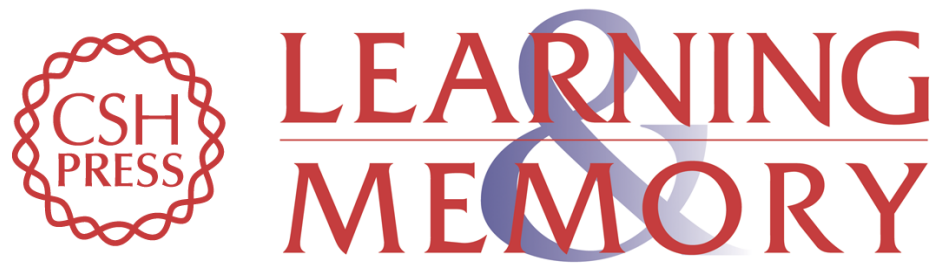

\section{Ventral lateral geniculate input to the medial pons is necessary for visual eyeblink conditioning in rats}

Hunter E. Halverson and John H. Freeman

Learn. Mem. 2010, 17:

Access the most recent version at doi:10.1101//m.1572710

References This article cites 45 articles, 12 of which can be accessed free at:

http://learnmem.cshlp.org/content/17/2/80.full.html\#ref-list-1

License

Email Alerting Receive free email alerts when new articles cite this article - sign up in the box at the Service top right corner of the article or click here. 